Abstract-Demographic parameters were derived from sectioned otoliths of John's Snapper (Lutjanus johnii) from 4 regions across $9^{\circ}$ of latitude and $23^{\circ}$ of longitude in northern Australia. Latitudinal variation in size and growth rates of this species greatly exceeded longitudinal variation. Populations of John's Snapper farthest from the equator had the largest body sizes, in line with James's rule, and the fastest growth rates, contrary to the temperaturesize rule for ectotherms. A maximum age of 28.6 years, nearly 3 times previous estimates, was recorded and the largest individual was 990 $\mathrm{mm}$ in fork length. Females grew to a larger mean asymptotic fork length $\left(L_{\infty}\right)$ than did males, a finding consistent with functional gonochorism. Otolith weight at age and gonad weight at length followed the same latitudinal trends seen in length at age. Length at maturity was $\sim 72-87 \%$ of $L_{\infty}$ and varied by $\sim 23 \%$ across the full latitudinal gradient, but age at first maturity was consistently in the range of $6-10$ years, indicating that basic growth trajectories were similar across vastly different environments. We discuss both the need for complementary reproductive data in age-based studies and the insights gained from experiments where the concept of oxygen- and capacity-limited thermal tolerance is applied to explain the mechanistic causes of James's rule in tropical fish species.

Manuscript submitted 29 June 2012. Manuscript accepted 10 July 2013. Fish Bull. 111:309-324.

doi: 10.7755/FB.111.4.2

The views and opinions expressed or implied in this article are those of the author (or authors) and do not necesarily reflect the position of the National Marine Fisheries Service, NOAA.

\title{
James's rule and causes and consequences of a latitudinal cline in the demography of John's Snapper (Lutjanus johnii) in coastal waters of Australia
}

\author{
Mike Cappo (contact author) ${ }^{1}$ \\ Ross J. Marriott ${ }^{2}$ \\ Stephen J. Newman² \\ Email address for contact author: mcappo@aims.gov.au \\ ${ }^{1}$ Australian Institute of Marine Science \\ PMB 3, Townsville MC \\ Townsville 4810 \\ Queensland, Australia \\ 2 Western Australian Fisheries and Marine Research Laboratories \\ Department of Fisheries \\ Government of Western Australia \\ P.O. Box 20 \\ North Beach 6920 \\ Western Australia, Australia
}

Body sizes generally increase across a range of taxa with increasing distance from the equator, a principle known as Bergmann's rule; another theory about variation of size by latitude, James's rule, applies this phenomenon within species (for review, see Blackburn et al., 1999). The potential existence of such an underlying latitudinal cline raises major ecological questions about 1) the mortality and lifetime reproductive contribution of adults throughout their geographic range, 2) the implications for recruitment rates at marginal latitudes, and 3) the implications for fishery harvests. James's rule has been well demonstrated in both cold temperate and tropical fish species (e.g., Choat and Robertson, 2002; Choat et al., 2003; Robertson et al., 2005a; Pörtner et al., 2008; Trip et al., 2008; Berumen et al., 2012), and the advent of warming oceans has caused an upsurge in interest in the underlying physiological mechanisms of this rule (Pörtner and Peck, 2010; Clark et al., 2012).

However, major equatorial gaps still remain in such descriptive knowledge of demographic processes for the large, economically important lutjanid snappers, lethrinid emperors, and serranid groupers, especially in the Indo-West Pacific, where most studies have been done south of $15^{\circ} \mathrm{S}$. Ecosystem "mass balance" models (sensu Pauly et al., 1993) and life history classifications used for estimating resilience (King and MacFarlane, 2003) are sensitive to estimates of maximum size, growth rate, and longevity. In data-poor tropical fisheries, these estimates are often derived from only one part of a species' distribution (e.g., Binohlan and Froese, 2009) or from a mix of parameters derived from different studies in separate regions (e.g., Pauly et al., 1993). Consequently, there is a need to investigate regional differences to determine whether growth trajectories and reaction norms (i.e., the pattern of phenotypic expression of a single genotype across a range of environments) such as age at maturity are conserved in populations along latitudinal gradients (see Arendt, 2011).

John's Snapper (Lutjanus johnii), is widely distributed in the Indo- 
West Pacific, extending from East Africa to Fiji, north to the Ryukyu Islands and south to Australia (Allen, 1985). In Southeast Asia, this species is called jenahak or ang cho and is important in both wild-harvest fisheries and sea-cage mariculture (Tanaka et al., 2011). In Australia, this species is known as "Golden Snapper" or "Fingermark" and is a dominant, large lutjanid of the nearshore community of reef fishes from the Kimberley region $\left(\sim 124^{\circ} \mathrm{E}\right)$ in northwestern Australia, across northern Australia, and down the Queensland coast to at least $23^{\circ} \mathrm{S}$ (Travers et al., 2009). Juvenile and younger adult John's Snapper generally are associated with the lower reaches of mangrove-lined estuaries (Kiso and Mahyam, 2003) and eventually move offshore toward fringing and coastal reefs (Tanaka et al., 2011). Large adults in Australia are found schooling in turbid waters around hard substrata and complex topography in muddy coastal areas and occasionally on deeper, sandier trawl grounds offshore (Marriott and Cappo, 2000).

Australia's northern coastline is mostly uninhabited by humans or sparsely populated and remote from domestic markets. The Northern Territory is the only state that reports landings of John's Snapper. The coastal hook-and-line fishery of the Northern Territory reported landings of only 8.64 metric tons (t) in 2009, $5.34 \mathrm{t}$ in 2010 , and $4.38 \mathrm{t}$ in 2011 (Northern Territory Government ${ }^{1}$ ). John's Snapper is a prized sportfish in Australia and Malaysia, but skilled fishing techniques and approaches, such as night fishing and live squid baits, often are required to catch one. Sportfishing and spearfishing interest in John's Snapper is expanding in northern Australia with both the development of charter operations in remote locations and the rapid development of marine electronics for use on small boats to echolocate fish. Most charter boat operators and many top anglers practice catch and release for this species.

Longevities of $<10$ years have been published for John's Snapper from the reading of scales (Andaman Sea; Druzhinin, 1970) and from a single length-frequency composition (Bay of Bengal; Khan, 1986). The growth parameters from these studies still compose the major information source for John's Snapper (FishBase, http://www.fishbase.org/search.php; Froese, 2011). Both techniques are well known to have serious bias where size is uncoupled from age and where under-aging can lead to a three-fold overestimation of natural mortality for lutjanids (Newman et al., 2000), thus inflating estimates of potential fishery yield.

The primary objectives of this study were, therefore, 1) to describe the age composition, growth, and mortality of John's Snapper on the basis of age estimates from sectioned otoliths; 2 ) to quantify spatial variability in the length, otolith weight at age, and gonad weight at length of populations of John's Snapper along a lati-

\footnotetext{
${ }^{1}$ Northern Territory Government. 2012. Fishery Status Reports 2011, 162 p. Northern Territory Government, Department of Primary Industry and Fisheries, Darwin, NT, Australia. Fishery Report No. 111. [Available from http://www. nt.gov.au/d/Content/File/p/Fish_Rep/FR111.pdf.]
}

tudinal gradient, and 3) to examine catch records for other large lutjanids for signs of latitudinal variation in maximum size in the Indo-West Pacific.

\section{Materials and methods}

\section{Sampling methods and locality}

Filleted fish frames or whole specimens (identified using Allen, 1985) were collected during the period of February 1989-April 2002 from fish processing facilities, research surveys, sportfishing charter operators, anglers, and spearfishing individuals in 4 regions: the coast of the Kimberley (Western Australia); the Arafura Sea (Northern Territory); coast of Cape York (Queensland); and the coast from Townsville to Cairns (Queensland) (Fig. 1). The fork lengths (FL) were recorded in millimeters, and, where whole fish were available $(n=129)$, whole weights $\left(W_{\mathrm{W}}\right)$ were measured in grams. Sagittae (hereafter, referred to as "otoliths") were removed from under the gill covers, washed, dried, weighed, and measured. Notable gaps in full information occurred because volunteers contributed mainly eviscerated fish frames. Of the 948 fish that were aged, 863 had reliable FL and 928 had reliable otolith weights. Sex was determined by macroscopic examination for 786 fish, but whole gonad weights $\left(W_{\mathrm{G}}\right)$ were measured, in grams, for only 277 of them.

\section{Estimation of fish age}

Three transverse sections were cut from otoliths embedded in resin with a low speed circular saw and diamond wafering blade in the vicinity of the primordium. The sections were $0.25-0.50 \mathrm{~mm}$ thick, depending on width of the otolith, and were lightly polished on wet ebony paper (1000 grade) and lapping film (9 and $3 \mu \mathrm{m}$ ). The sections were mounted in resin on $\mathrm{mi}-$ croscope slides under cover slips. Opaque zones-annuli or annual growth rings-were counted along the ventral margin of the sulcus acousticus under reflected light against a dark background (see Newman et al., 2000). These zones are deposited annually from spring to early summer (Cappo et al., 2000). Categorization of otolith margins indicated that deposition of opaque zones occurred over a period of 9 months, with a low peak in October for the eastern regions (Cape York and north Queensland).

The index of average percent error (IAPE) (Beamish and Fournier, 1981) among readers and readings (eastern regions: $\mathrm{IAPE}=4.18 \pm 1.01 \%, n=55$; Kimberley: IAPE $=3.96 \pm 0.92 \%, n=55$ ), was below a benchmark IAPE of $5 \%$ acceptable for long-lived species (Allman et al., 2005), and there was no significant drift in increment counts in age bias plots (see Campana et al., 1995).

A preliminary analysis of monthly mean gonadosomatic index (GSI) values (percentages) was made to 


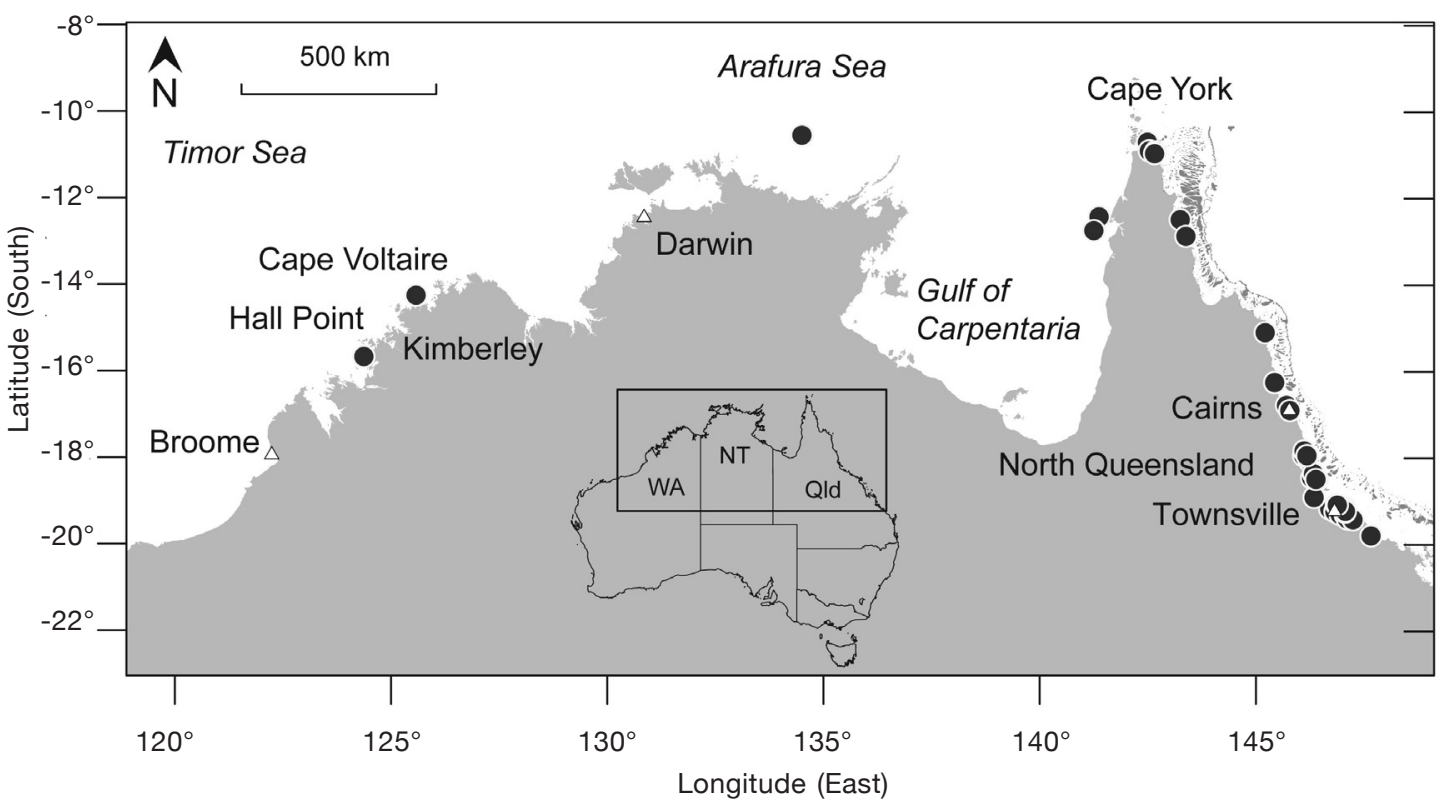

Figure 1

Map of sampling locations (circles) for an examination of a latitudinal cline in the demography of John's Snapper (Lutjanus johnii) collected over the period of February 1989-April 2002 in 4 regions in northern Australia: Kimberley, Arafura Sea, Cape York, and north Queensland. Triangles indicate major centers of human inhabitation.

estimate birth months with measurements of gonad weight available for 176 eastern fish. First, $W_{\mathrm{W}}$ estimates were calculated from FL $\left(L_{\mathrm{F}}\right)$ measurements using this equation:

$$
W_{\mathrm{W}}=\mathrm{a} \times L_{\mathrm{F}}{ }^{\mathrm{b}}
$$

with a nonlinear regression: $a=7.701 \times 10^{-5} \pm 2.046 \times 10^{-}$ ${ }^{5}, \mathrm{~b}=2.741 \pm 0.0401$, coefficient of multiple determination $\left(R^{2}=0.987, n=77\right)$. Equation 1 was applied to predict whole weight for all fish in the pooled subsample $\left(\mathrm{W}_{\mathrm{w} \text { (pred) }}\right)$, and GSI values were calculated with the following equation:

$$
G S I=\left(W_{\mathrm{G}} /\left(W_{\mathrm{w}(\text { pred })}-W_{\mathrm{G}}\right)\right) \times 100 .
$$

Equation 2 showed higher GSI values in the austral summer after October; therefore, the nominal birth date for John's Snapper in this study was chosen to be Oct. 1. Individual fish ages (in years) were the number of opaque increments (years) plus fractions of a year elapsed between sampling and Oct. 1 .

\section{Estimation of mortality}

The instantaneous rate of total mortality $(Z)$ was derived with the maximum age in years $\left(t_{\max }\right)$ from the equation of Hoenig (1983):

$$
\log _{e} Z=1.46-1.01 \log _{e} t_{\max }
$$

This estimate of $Z$ is from a lightly exploited population; therefore, the estimate of natural mortality $(M)$ should be similar to $Z$. It has been applied as a reasonable approximation for unfished or lightly fished tropical demersal fishes in the absence of enough samples for catch curve analysis (Newman et al., 2000).

\section{Growth parameters}

The von Bertalanffy growth function (VBGF) was fitted to estimates of length at age through the use of nonlinear least squares estimation. The VBGF is defined by the equation

$$
L_{t}=L_{\infty}\left\{1-e^{-K\left(t-t_{0}\right)}\right\},
$$

where $L_{t}=$ mean FL (in millimeters) of fish of age $t$ (in years);

$L_{\infty}=$ asymptotic mean length;

$K=$ is a rate constant that determines the rate at which $L_{t}$ approaches $L_{\infty}$;

$t=$ age of a fish; and

$t_{0}=$ the hypothetical age at which the mean length is zero.

The fit of the VBGF to different data sets was compared by using the likelihood ratio test for coincident curves (Cerrato, 1990) across comparable age ranges (Haddon, 2001) and analysis of covariance (ANCOVA) with type-III sums of squares and with $\log _{e}$-transformed age (year) as the linear covariate. This ANCOVA allowed for testing of an interaction of sex $\times$ region and accounted for type-I errors. 


\section{Otolith weight at age and gonad weight at length}

Nonlinear least squares estimation also was used to fit second-order polynomial functions to regional estimates of otolith weight at age $t$ (in years) and an exponential function to gonad weight $\left(W_{G}\right)$ at $\mathrm{FL}\left(L_{\mathrm{F}}\right.$ in millimeters).

The functions were defined with relevant starting parameters $(a, b, c)$ by the following equations:

$$
\begin{gathered}
\text { Otolith weight }=\mathrm{a}+\mathrm{b}(t)+\mathrm{c}\left(t^{2}\right) \\
\text { Gonad weight }=e^{\left(\mathrm{a}+\mathrm{b}\left(L_{\mathrm{F}}\right)\right)} .
\end{gathered}
$$

Quantile-quantile normal plots and Cook's Distance were used to identify outliers for exclusion, and plots of residuals were used to test for lack of homogeneity in variances. Comparisons in the 2 responses by sex or region were restricted to the range of explanatory data (sizes or ages) common to each level in the comparison with likelihood ratio tests for coincident curves and ANCOVA with type-III sums of squares. $\log _{e}$ transformations were used to linearize the gonad weight and otolith weight covariates for the ANCOVA. Data from the Arafura Sea were too few for use in these tests and were compared visually with the other regions.

\section{Australian and international fishing records}

An Internet search for record sizes of John's Snapper and other large lutjanids landed by line and spearfishing was conducted for countries in the Indo-West Pacific, but only world and Australian records were available. The 2011 records maintained by the International Game Fishing Association (IGFA), Australian National Sportfishing Association (ANSA), Australian Angler's Association (AAA), and Australian Underwater Federation (AUF), were used

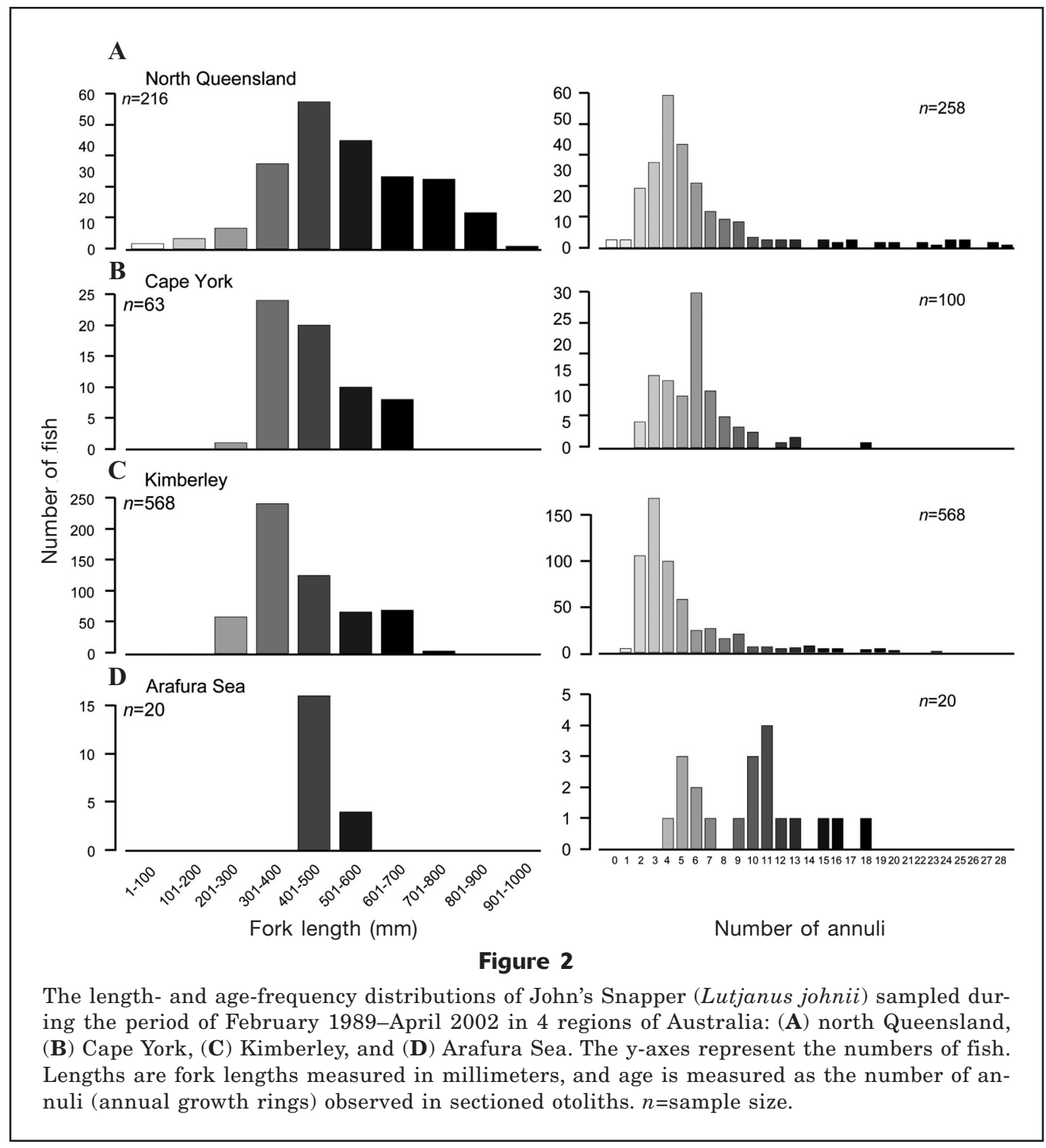




\section{Table 1}

Fitted parameter estimates for the von Bertalanffy growth models for males (M), females (F), and all John's Snapper (Lutjanus johnii) sampled from the Kimberley, north Queensland, and Cape York regions in Australia during the period of February 1989-April 2002 (see Fig. 3, for graphs of growth curves by sex and region). $L_{\mathrm{t}}=$ mean fork length $(\mathrm{mm})$ of fish of age $t$ (years), $L_{\infty}=$ asymptotic mean length $(\mathrm{mm}), t_{0}=$ the hypothetical age at which the mean length is zero, $K$ is the growth coefficient at which $L_{\mathrm{t}}$ approaches $L_{\infty}$. Standard errors of fitted parameter estimates are reported in parentheses, and the coefficient of multiple determination $\left(R^{2}\right)$ and sample size $(n)$ are also given.

\begin{tabular}{lrcccc}
\hline Region & $n$ & $L_{\infty}$ & $K$ & $t_{0}$ & $R^{2}$ \\
\hline Kimberley (M) & 255 & $677.1(20.53)$ & $0.17(0.02)$ & $-0.81(0.33)$ & 0.76 \\
Kimberley (F) & 294 & $739.6(27.05)$ & $0.16(0.02)$ & $-0.62(0.29)$ & 0.79 \\
North Queensland (M) & 80 & $819.7(25.27)$ & $0.18(0.02)$ & $-0.32(0.36)$ & 0.85 \\
North Queensland (F) & 74 & $851.4(37.37)$ & $0.21(0.03)$ & $0.34(0.29)$ & 0.83 \\
Kimberley & 568 & $698.0(14.48)$ & $0.18(0.01)$ & $-0.51(0.20)$ & 0.79 \\
North Queensland & 216 & $843.5(15.66)$ & $0.19(0.01)$ & $0.02(0.16)$ & 0.87 \\
Cape York & 63 & $685.1(50.04)$ & $0.18(0.05)$ & $-0.82(0.80)$ & 0.74 \\
& & & & & \\
\end{tabular}

to plot the maximum weights of John's Snapper and 6 other large lutjanids with latitude. These other species were Mangrove Jack (Lutjanus argentimaculatus), Twospot Snapper (L. bohar), Malabar Snapper (L. malabaricus), Emperor Snapper (L. sebae), Chinaman Fish (Symphorus nematophorus), and Green Jobfish (Aprion virescens).

\section{Results}

\section{Length and age distributions}

Samples from north Queensland had the smallest (55 mm FL) and largest (990 mm FL) fish, a higher modal FL (401-500 $\mathrm{mm}$ ) than the samples from the Kimberley and Cape York regions (301-400 mm FL), and a much higher proportion of very large John's Snapper than samples from the other 3 regions (Fig. 2). The overall proportion of samples that were older than 8 years in the Kimberley region (11.6\%) was smaller than the proportion of such samples in the north Queensland region (18.2\%) but similar to the proportion in the Cape York region (11\%). The modal age (4 years) for fish from north Queensland was higher than the modal age of fish from Kimberley (3 years), and the 6-year age class was most prevalent in the samples from Cape York. The oldest year classes were from north Queensland (28 year), Kimberley (23 year), and Cape York (18 year).

\section{Mortality}

The maximum observed age $\left(t_{\max }\right)$ of 28.6 years (a male) was used to produce an estimate of $Z=0.146$ year $^{-1}$ with the Hoenig (1983) equation for the north Queensland region. Estimates of $Z$ were not calculated for the other regions because of concerns that the $t_{\max }$ values might be skewed by a lack of older year classes that represented undersampling and not truncation of the true age distribution.

\section{Growth}

The von Bertalanffy growth curves fitted to length-atage data revealed a relatively moderate growth trend (Fig. 3). This trend was reflected in estimates for the $K$ curvature parameter, which ranged from 0.17 to 0.21 year $^{-1}$ (Table 1). Relatively rapid growth from 0.5 year to 5-7 years was followed by a slower phase after approximately 7-10 years. Asymptotic growth began at approximately 18-20 years (Fig. 3).

Females were estimated to grow to a larger average asymptotic length $\left(L_{\infty}\right)$ in the Kimberley and north Queensland regions (Fig. 3; Table 1). However, sex-specific differences in growth curvature, $K$, were inconsistent between regions; a higher $K$ value was evident for males than for females in the Kimberley region and a lower $K$ value for males than for females in north Queensland (Table 2). The north Queensland $L_{\infty}$ was $17.3 \%$ (145.5 mm FL) and 18.8\% (158.4 mm FL) higher than the $L_{\infty}$ for samples from the Kimberley and Cape York regions (Table 1; Fig. 3).

Apparent differences in growth trends between sexes and regions were observed to be statistically significant in both the likelihood ratio and ANCOVA tests (Table 2 ). Significant differences between sex-specific curves were detected within each of the Kimberley and north Queensland regions (Table 2). The lack of significant interaction for sex $\times$ region indicates that the larger $L_{\infty}$ for females than for males was consistent among regions.

Likelihood ratio tests revealed significant differences in growth curves between samples from the 


\section{A}

Kimberley: Females
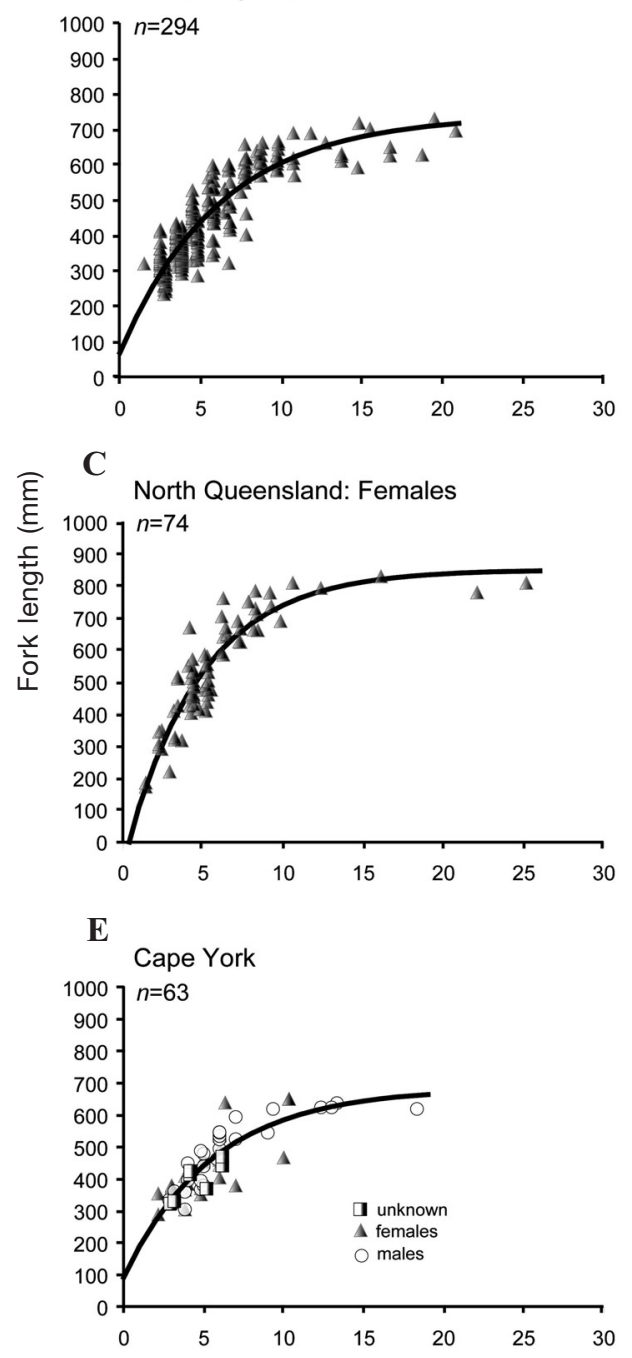

B

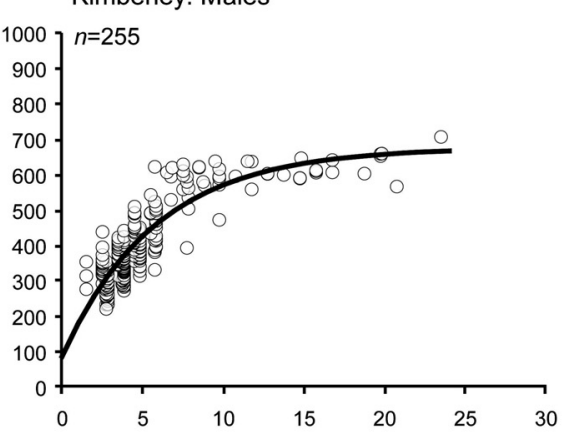

D
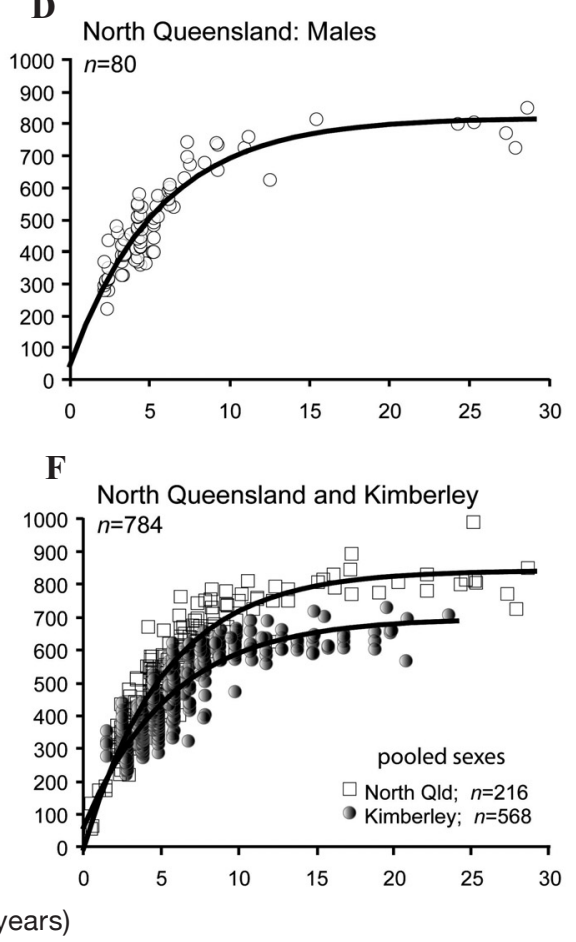

Figure 3

Fits of the von Bertalanffy growth function by sex and region for John's Snapper (Lutjanus johnii) sampled during the period of February 1989-April 2002 in northern Australia. Females (gray triangles) and males (open circles) are distinguished in separate curves for the $(\mathbf{A}, \mathbf{B})$ Kimberley and $(\mathbf{C}, \mathbf{D})$ north Queensland regions. A single curve describes the small sample size $(n)$ for (E) Cape York, where a large proportion of fish were of unknown sex (shaded squares). Significantly different growth curves describe eastern and western fish (F) when sexes were pooled. For more information on growth estimates and comparisons from these models, see Tables 1 and 2 .

Kimberley and north Queensland regions for each sex, and a significant main effect of region on the slope of transformed length at age (Table 2). The larger $L_{\infty}$ and $K$ for samples from north Queensland, therefore, were significantly different from those values for samples from the Kimberley and Cape York regions, but there was no significant difference between values for Cape York and Kimberley fish.

\section{Otolith weight at age}

The sagittae of John's Snapper are exceptionally large, and the largest otolith weighed in this study exceeded $5 \mathrm{~g}$. Second-order polynomials provided the best fits for otolith weight at age with $R^{2}$ values of $0.77-0.95$ (Table 3 ; Fig. 4). Very small values for the slope parameter c indicate that these relationships were close to linear 


\section{Table 2}

Comparison of regional growth data for John's Snapper (Lutjanus johnii) from our study of a latitudinal cline in the demography of this species in Australia. Likelihood ratio tests, each with 3 degrees of freedom (df), were performed for coincidence of curves (Curves). Tests of the probability $(P)$ of differences among slopes $(\beta)$ and intercepts $(\alpha)$ were made for sex and region with 2 -way analysis of covariance (ANCOVA) of fork length $(\mathrm{mm})$ against $\log _{e}$ (age) for samples from the Kimberley and north Queensland regions (df numerator:df denominator=1:672). Tests of slopes and intercepts were made only for region for Cape York and Kimberley with 1-way ANCOVA $(\mathrm{df}=1: 616)$ and for Cape York and north Queensland $(\mathrm{df}=1: 256) . P=$ probability of null hypothesis being true. If the chi-squared goodness of fit statistic $\left(\chi^{2}\right)$ is large, the null model is a poor fit to the curve. The $F$ statistic is the ratio of between-group mean square values to the within-group mean square values for slopes and intercepts.

\begin{tabular}{llllr}
\hline & Factor & Parameter & Test statistic & $P$ \\
\hline Excluding Cape York data & & & & \\
Kimberley & Sex & Curves & $\chi^{2}=14.42$ & 0.00 \\
North Queensland & Sex & Curves & $\chi^{2}=8.70$ & 0.03 \\
Males & Region & Curves & $\chi^{2}=80.68$ & $<0.00$ \\
Females & Region & Curves & $\chi^{2}=99.58$ & $<0.00$ \\
Kimberley, north Queensland & Sex & $\beta$ & $F=9.47$ & 0.00 \\
Kimberley, north Queensland & Region & $\beta$ & $F=35.89$ & $<0.00$ \\
Kimberley, north Queensland & Sex $\times$ Region & $\beta$ & $F=1.07$ & 0.30 \\
Kimberley, north Queensland & Sex & $\alpha$ & $F=4.51$ & 0.03 \\
Kimberley, north Queensland & Region & $\alpha$ & $F=3.00$ & 0.08 \\
Kimberley, north Queensland & Sex $\times$ Region & $\alpha$ & $F=0.67$ & 0.41 \\
Including Cape York data: sexes pooled & & & & \\
Cape York, Kimberley & Region & Curves & $\chi^{2}=2.06$ & 0.56 \\
Cape York, Kimberley & Region & $\beta$ & $F=1.45$ & 0.23 \\
Cape York, Kimberley & Region & $\alpha$ & $F=1.95$ & 0.16 \\
Cape York, north Queensland & Region & Curves & $\chi^{2}=83.44$ & $<0.00$ \\
Cape York, north Queensland & Region & $\beta$ & $F=19.43$ & $<0.00$ \\
Cape York, north Queensland & Region & $\alpha$ & $F=3.98$ & 0.05 \\
& & & & \\
\hline
\end{tabular}

(Table 3). Departures from a linear relationship were evident for older fish (>10 years), where the rate of otolith weight accretion appeared to decline with age (Fig. 4).

Tests that spanned the widest age range, for the north Queensland region, showed no significant effects of sex on accretion rate, but there were significant differences in the coincidence of curves, slopes, and intercepts for pairwise comparisons of age ranges common between north Queensland and other regions (Table 4). Evidence of a difference in otolith weight at age between results for Kimberley and Cape York fish was equivocal because the fitted curves were not coincident, but the slopes and intercepts were not significantly different (Table 4). Cape York and Kimberley curves were intermediate between those from the north Queensland and Arafura Sea regions, showing a cline for an increasing rate of accretion of otolith weight with age and distance from the equator by about $0.2 \mathrm{~g}$ per degree of latitude for the oldest fish. Visual comparison of the regional fits with data from the Arafura Sea region showed an approximate two-fold difference in otolith weight at age beyond 10 years for north Queensland fish (Fig. 5).

\section{Gonad weight at length and maturity}

Exponential models provided the best fits for gonad weight at length (Table 5; Fig. 4), but the lack of data on gonad weights elsewhere severely restricted the tests in pairwise comparisons. There were no significant effects of sex for samples from north Queensland (Table 6), a finding that is not coincident with the Kimberley and Cape York fits. The tests on slopes and intercepts, however, were not significant.

For fish with gonads that weighed $\geq 20 \mathrm{~g}$, maturity was evident from macroscopic classification (Fig. 4). Minimum lengths and ages for the females of these mature fish were $690 \mathrm{~mm}$ FL and 9.83 years for north Queensland, $549 \mathrm{~mm}$ FL and 7.75 years for Kimberley, and $640 \mathrm{~mm} \mathrm{FL}$ and 6.3 years for Cape York. Minimum lengths and ages for males that had gonads that weighed $\geq 20 \mathrm{~g}$ were $590 \mathrm{~mm} \mathrm{FL}$ and 6.16 years for north Queensland, $590 \mathrm{~mm} \mathrm{FL}$ and 9.75 years for Kimberley, and $620 \mathrm{~mm}$ FL and 9.33 years for Cape York (Fig. 4). In contrast, the Arafura Sea fish appeared to develop earlier. Fish sampled in that region 


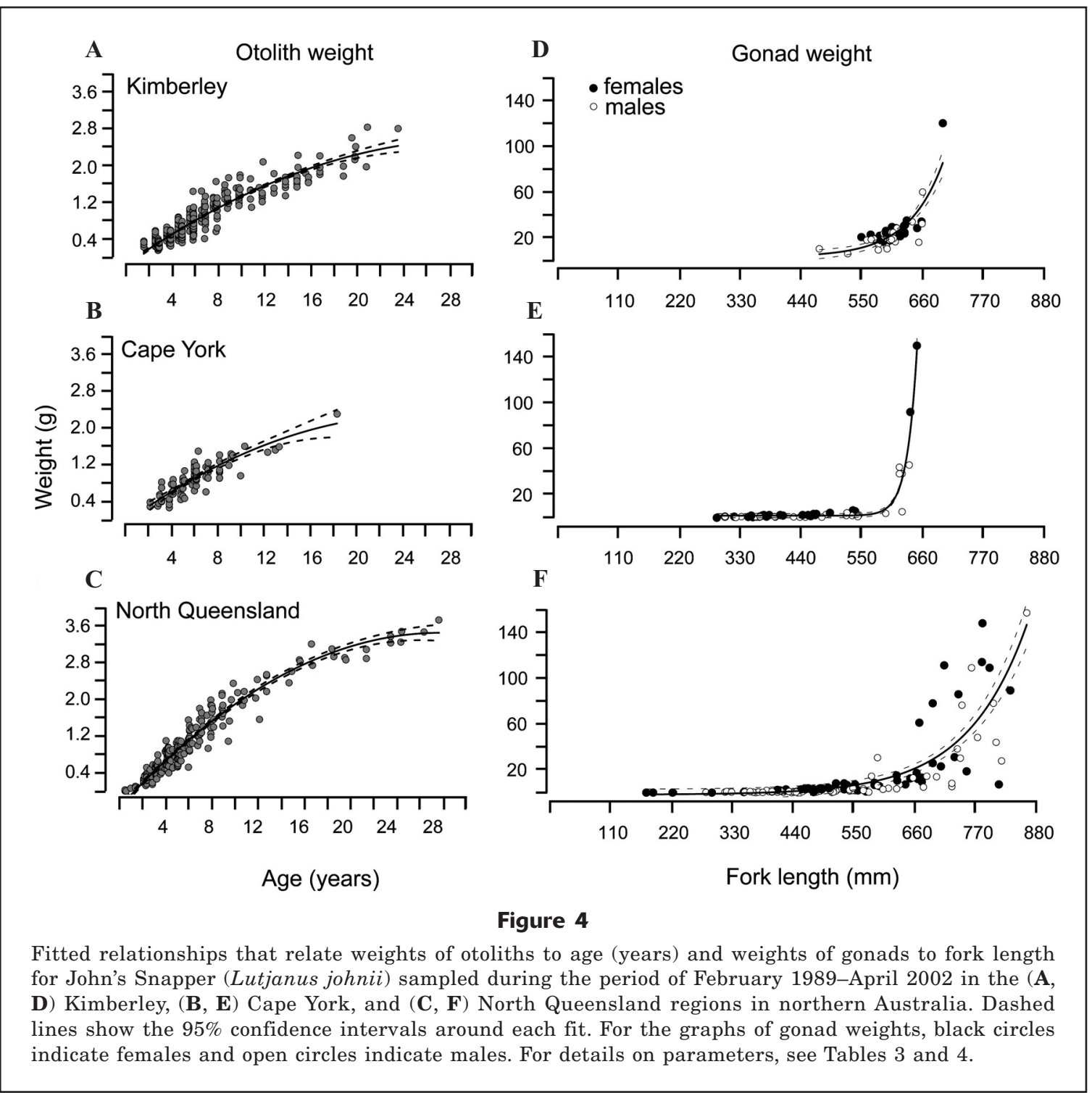

had ovaries $\geq 20 \mathrm{~g}$ at $448 \mathrm{~mm} \mathrm{FL}$ (5.0 years) and testes $\geq 20$ g at $472 \mathrm{~mm} \mathrm{FL} \mathrm{(10.91} \mathrm{years)} \mathrm{(Fig.} \mathrm{5).}$

These preliminary data indicate the difference in length at maturity may be up to $24 \%$ between the northernmost and southernmost samples, but age at maturity (6-10 years) may be similar among regions, depending on sex. The north Queensland females and males matured at $\sim 81 \%$ and $\sim 72 \%$ of $L_{\infty}$, respectively, and for samples from the Kimberley region they matured at $\sim 74 \%$ and $\sim 87 \%$, respectively.

\section{Latitudinal spread of catch records}

Catch records for Indo-West Pacific lutjanids indicate that the latitudes farthest from the equator produced the largest individuals for 7 species, in a steeply concave, "U-shaped" relationship, but we could not locate any records for other equatorial countries to fit statis- tical relationships (Fig. 6). Most records were obtained from landings in the southern hemisphere, but several world records came from Japan. The largest records for John's Snapper show a steep rise over about $8^{\circ} \mathrm{S}$ from $7.2 \mathrm{~kg}$ in Darwin (Australian all-tackle [AAA] record) to weights of $10.5 \mathrm{~kg}$ (97 $\mathrm{cm}$ total length, world all-tackle [IGFA] record), $12.420 \mathrm{~kg}$ (6-kg line-class [ANSA] record), and $12.0 \mathrm{~kg}$ (spearfishing [AUF] record) near Cairns. The maximum published weight from scientific samples is $4.7 \mathrm{~kg}$ for a 71-cm John's Snapper from the Andaman Sea (Druzhinin and Hlaing, 1972).

\section{Discussion}

Our detection of latitudinal clines in $L_{\infty}$ of John's Snapper with distance from the equator is explained 
Table 3

Parameters of the functions that relate otolith weight (grams) to age ( $t$ years) for males $(\mathrm{M})$, females $(\mathrm{F})$, and all John's Snapper (Lutjanus johnii) sampled in northern Australia over the period of February 1989-April 2002. Data were pooled from 3 regions with nonlinear least-squares estimation of otolith weight $=\mathrm{a}+\mathrm{b}(t)$ $+\mathrm{c}\left(t^{2}\right)$. Standard errors of parameters are shown in parentheses, and the range in ages (years), sample size $(n)$, and coefficient of multiple determination $\left(R^{2}\right)$ are also given.

\begin{tabular}{llrcccr}
\hline & $t$ range (years) & $n$ & $\mathrm{a}$ & $\mathrm{b}$ & $\mathrm{c}$ & $R^{2}$ \\
\hline North Queensland (M) & $2.16-28.58$ & 84 & $-0.31(0.06)$ & $0.25(0.02)$ & $-0.00(0.00)$ & 0.95 \\
North Queensland (F) & $1.41-25.16$ & 80 & $-0.34(0.08)$ & $0.27(0.02)$ & $-0.01(0.00)$ & 0.90 \\
North Queensland & $1.41-28.58$ & 244 & $-0.34(0.05)$ & $0.26(0.01)$ & -0.00 & 0.91 \\
Kimberley & $1.5-23.5$ & 563 & $-0.16(0.02)$ & $0.18(0.01)$ & -0.00 & 0.89 \\
Cape York & $2.16-18.33$ & 99 & $-0.07(0.09)$ & $0.18(0.02)$ & $-0.00(0.00)$ & 0.77
\end{tabular}

in theories of variation in body size of ectotherms in relation to geography (James's rule; Blackburn et al., 1999) and temperature (temperature-size rule; Atkinson, 1994). However, our estimation of faster growth rates in cooler water farther from the equator contradicts the temperature-size rule. Here, we discuss the major explanations for the patterns we observed through the use of prevailing ecological theories, and we consider the effects of our revised estimates of parameters for the VBGF on studies of life history.

\section{Explanations of James's rule for tropical fishes}

Similar clines in maximum size and growth have been documented for some sedentary coral reef species at much larger and smaller latitudinal scales, but, in the case of some lutjanids, the same trends have always been interpreted as an effect of fishing, regional differences in productivity of habitats, or the evolution of separate stocks. For example, Allman and Goetz (2009) and Burton (2001) reported that mean size at age in Gray Snapper (Lutjanus griseus) in Florida in-

Table 4

Summary of regional comparisons of otolith weight at age for John's Snapper (Lutjanus johnii) from this study of a latitudinal cline in the demography of this species in Australia. Likelihood ratio tests, each with 3 degrees of freedom, were performed for coincidence of curves (Curves). Tests of differences among slopes $(\beta)$ and intercepts $(\alpha)$ were made by using 1-way analysis of covariance of otolith weight against $\log _{e}$ (age). All tests were conducted over age ranges present at both levels of the pairwise comparisons. The number of samples ( $n$, otolith weights) is shown in parentheses for each member of the pairs, with the common age range in years $(\mathrm{yr}) . P=$ probability of null hypothesis being true. If the chi-squared goodness of fit statistic $\left(\chi^{2}\right)$ is large, then the null model is a poor fit to the curve. The $F$ statistic is the ratio of between-group mean square values to the within-group mean square values for slopes and intercepts. Inf=infinity.

\begin{tabular}{llll}
\hline Region; age range & Parameter & Test statistic & $P$ \\
\hline
\end{tabular}

North Queensland

Male (80), Female (77); 2.16-25.16 yr

North Queensland (227), Kimberley (563); 1.5-23.5 yr

North Queensland (221), Cape York (98); 2.16-18.3 yr

Cape York (96), Kimberley (550); 2.16-18.3 yr

\begin{tabular}{clr} 
Curves & $\chi^{2}=\operatorname{Inf}$ & \multicolumn{1}{l}{1} \\
$\beta$ & $F=0.59$ & 0.44 \\
$\alpha$ & $F=0.33$ & 0.57 \\
Curves & $\chi^{2}=349.19$ & $<0.00$ \\
$\beta$ & $F=168.48$ & $<0.00$ \\
$\alpha$ & $F=69.30$ & $<0.00$ \\
Curves & $\chi^{2}=86.19$ & $<0.00$ \\
$\beta$ & $F=168.48$ & $<0.00$ \\
$\alpha$ & $F=69.30$ & $<0.00$ \\
Curves & $\chi^{2}=23.21$ & $<0.00$ \\
$\beta$ & $F=0.31$ & 0.58 \\
$\alpha$ & $F=1.59$ & 0.21
\end{tabular}




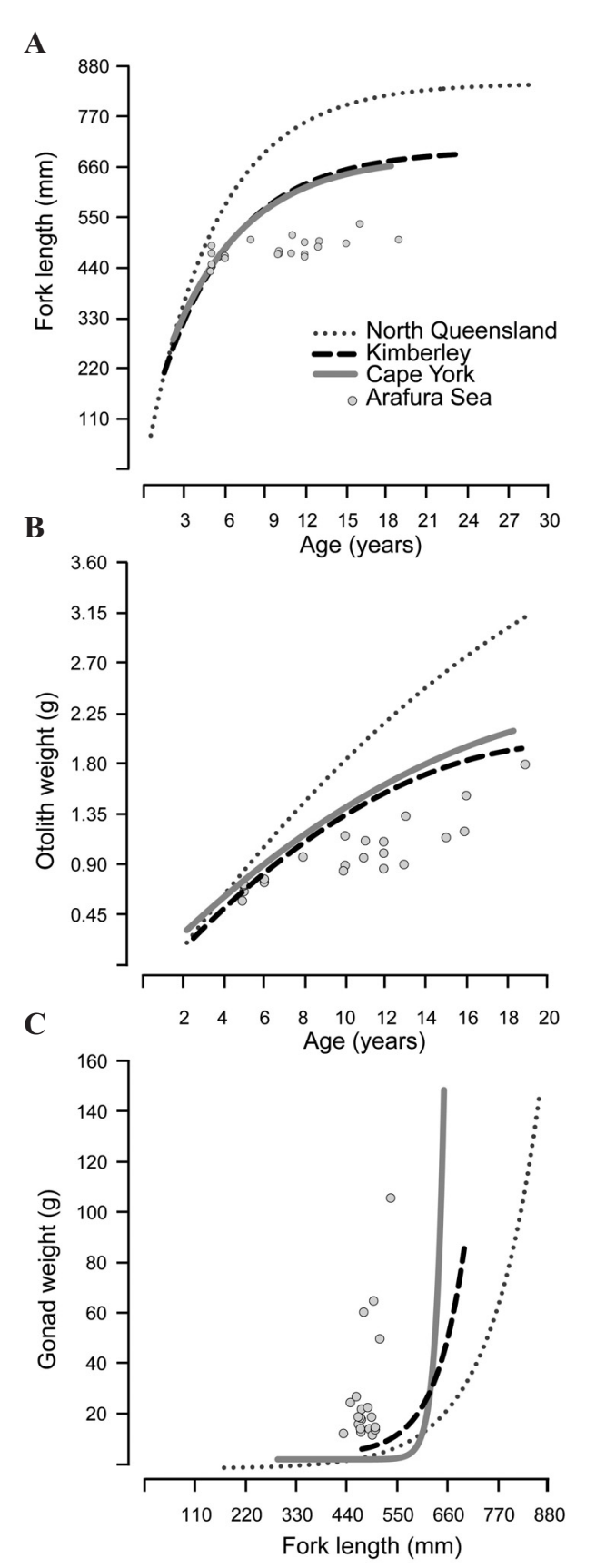

Figure 5

Comparisons of parameters by region, and fits of Arafura Sea data points, for John's Snapper (Lutjanus johnii) sampled during the period of February 1989-April 2002 in 4 regions of Australia-north Queensland, Kimberley, Cape York, and Arafura Sea: (A) fork length $(\mathrm{mm})$ at age (years) with von Bertalanffy growth function (sexes pooled; see Table 2); (B) otolith weight at age with first-order polynomials (see Table 3); and (C) gonad weight at fork length with exponential relationships (see Table 5). creased with distance from the equator, but they invoked major regional differences in exploitation rate as an explanation. At a smaller latitudinal scale, Saari (2011) concluded that Red Snapper (L. campechanus) from northern Texas and Alabama reach significantly larger $L_{\infty}$ than do Red Snapper from southern Texas and northwestern Florida. Saari (2011) discussed severe overfishing as the primary cause of the difference, as well as differences in environmental factors, fishing behavior between sectors, habitat-preference, and management regimes. In eastern Indonesia, the Crimson Snapper (L. erythropterus) and Malabar Snapper grow faster than their conspecifics in northern Australia, but Fry and Milton (2009) interpreted this pattern in relation to the genetic evidence for separate stocks. Mangrove Jack at the southern end of their Australian range have faster juvenile growth and are larger at a given age, but Russell et al. ${ }^{2}$ were concerned that sample sizes were too small for any inferences to be made from such observations.

There is no doubt that heavy fishing can affect body sizes of fishes across latitudes. Throughout the 1970s, there was a ten-fold increase in mean body size of 326 fish species from low to high latitudes in the North Atlantic. However, this trend began to weaken under heavy fishing pressure in the early 1980s, and, by 1991 , mean body sizes had declined steeply to the extent that a gradient was no longer detectable (Fisher et al., 2010). This homogenization of community size structures was a breakdown of Bergmann's rule that Fisher et al. (2010) predicted will lead to declining stability in populations, communities, and ecosystems.

The earliest explanations for James's rule concerned a quandary posed by the temperature-size rule (Atkinson, 1994): for most ectotherms, decreased nutrition and decreased temperature both reduce growth rates, but each affects maturity differently. Decreased nutrition results in delayed maturity at a smaller size, yet decreased temperature usually results in delayed maturity at a larger size. This puzzle led Berrigan and Charnov (1994) to propose that the effects of temperature on maturity are associated with the existence of a negative correlation between $L_{\infty}$ and the growth coefficient, $K$, in the VBGF.

In contrast, the latitudinal studies of tropical fish growth at the largest scales, over $56^{\circ}$ of latitude for Ocean Surgeon (Acanthurus bahianus) and $14^{\circ}$ of latitude for Stoplight Parrotfish (Sparisoma viride), have shown that growth rate is faster in cooler waters (22.6$28.1^{\circ} \mathrm{C}$ ), not slower. Maximum age, adult survivorship, terminal size, and absolute growth rate are inversely related to temperature in populations of Ocean Sur-

\footnotetext{
2 Russell, D. J., A. J. McDougall, A. S. Reicher, J. R. Ovenden, and R. Street. 2003. Biology, management and genetic stock structure of mangrove jack (Lutjanus argentimaculatus) in Australia, 198 p. Queensland Department of Primary Industries, Brisbane, Australia. [Available from http:// era.deedi.qld.gov.au/3119/1/BiologyManGeneticStock_report_ final $\% 5 \mathrm{~B} 1 \% 5 \mathrm{D}$-sec.pdf.]
} 


\section{Table 5}

Parameters of the functions relating gonad weight (grams) to fork length (FL) for John's Snapper (Lutjanus johnii) sampled in 3 regions of Australia over the period of February 1989-April 2002. Nonlinear least-squares estimation was calculated with the following equation: gonad weight $=e^{\left(\mathrm{a}+\mathrm{b}\left(L_{\mathrm{F}}\right)\right)}$. Standard errors of parameters are shown in parentheses, and the range in FL $\left(L_{\mathrm{F}}\right)$, sample size $(n)$, and coefficient of multiple determination $\left(R^{2}\right)$ are also given.

\begin{tabular}{lcrccc}
\hline Region; sex & $L_{F}$ range $(\mathrm{mm})$ & $n$ & $\mathrm{a}$ & $\mathrm{b}$ & $R^{2}$ \\
\hline North Queensland (Male) & $222-860$ & 67 & $-5.24(0.99)$ & $0.01(0.00)$ & 0.75 \\
North Queensland (Female) & $173-830$ & 60 & $-2.27(1.08)$ & $0.01(0.00)$ & 0.57 \\
North Queensland & $173-860$ & 127 & $-2.98(0.75)$ & $0.01(0.00)$ & 0.60 \\
Kimberley & $473-696$ & 60 & $-6.49(0.69)$ & $0.02(0.00)$ & 0.68 \\
Cape York & $290-652$ & 56 & $-31.64(2.19)$ & $0.06(0.00)$ & 0.96 \\
& & & & & \\
\end{tabular}

geon (Robertson et al., 2005a) and there are no indications of consistent effects of fishing on longevity or adult survivorship (Robertson et al., 2005b). In relation to Berrigan and Charnov's (1994) commentary, it is important to note that there was no sign of a negative relationship between locality-specific $L_{\infty}$ and $K$ in fig. 5 of Robertson et al. (2005a) for Ocean Surgeon, but such a negative relationship was noted for Stoplight Parrotfish in fig. 4 of Choat et al. (2003).
Counter-gradient variation in growth rates has been proposed to explain this contradiction of the temperature-size rule. This counter-gradient variation occurs where genetic and environmental influences on phenotypes oppose one another to produce metabolic compensation (Conover et al., 1997). Various physiological rates and processes are now known to be elevated to counteract the dampening effect of reduced temperature and diminished length of the optimal season for

\section{Table 6}

Comparison of regional summaries of gonad weight at length for John's Snapper (Lutjanus johnii) from our study of a latitudinal cline in the demography of this species in Australia. Likelihood ratio tests, each with 2 degrees of freedom (df) were performed for coincidence of curves. Tests of differences among slopes $(\beta)$ and intercepts $(\alpha)$ were made by using 1 -way analysis of covariance of gonad weight against $\log _{e}$ (age). All tests were conducted over age ranges in fork length (FL) present in both levels of the pairwise comparisons. The number of samples ( $n$, shown in parentheses) and gonad weights is shown for each member of a pair, and the common length range in millimetres is also given. $P$ =probability of null hypothesis being true. If the chi-squared goodness-of-fit statistic $\left(\chi^{2}\right)$ is large, the null model is a poor fit to the curve. The $F$ statistic is the ratio of between-group mean square values to the within-group mean square values for slopes and intercepts. Inf=infinity.

\begin{tabular}{lccr}
\hline Region; fork length range & Parameter & Test statistic & $P$ \\
\hline North Queensland & & & \\
$\quad$ Male (66), Female (57); 222-830 mm & Curves & $\chi^{2}=$ Inf & 1 \\
& $\beta$ & $F=0.08$ & 0.77 \\
& $\alpha$ & $F=0.60$ & 0.44 \\
Regions & & & \\
North Queensland (60), Kimberley (60); 473-696 mm & Curves & $\chi^{2}=74.17$ & $<0.00$ \\
& $\beta$ & $F=1.05$ & 0.31 \\
& $\alpha$ & $F=3.24$ & 0.07 \\
North Queensland (89), Cape York (56); 290-652 mm & Curves & $\chi^{2}=281.74$ & $<0.00$ \\
& $\beta$ & $F=2.24$ & 0.14 \\
& $\alpha$ & $F=0.55$ & 0.46 \\
Kimberley (55), Cape York (22); 473-652 mm & Curves & $\chi^{2}=157.12$ & $<0.00$ \\
& $\beta$ & $F=25.74$ & $<0.00$ \\
& $\alpha$ & $F=28.25$ & $<0.00$
\end{tabular}




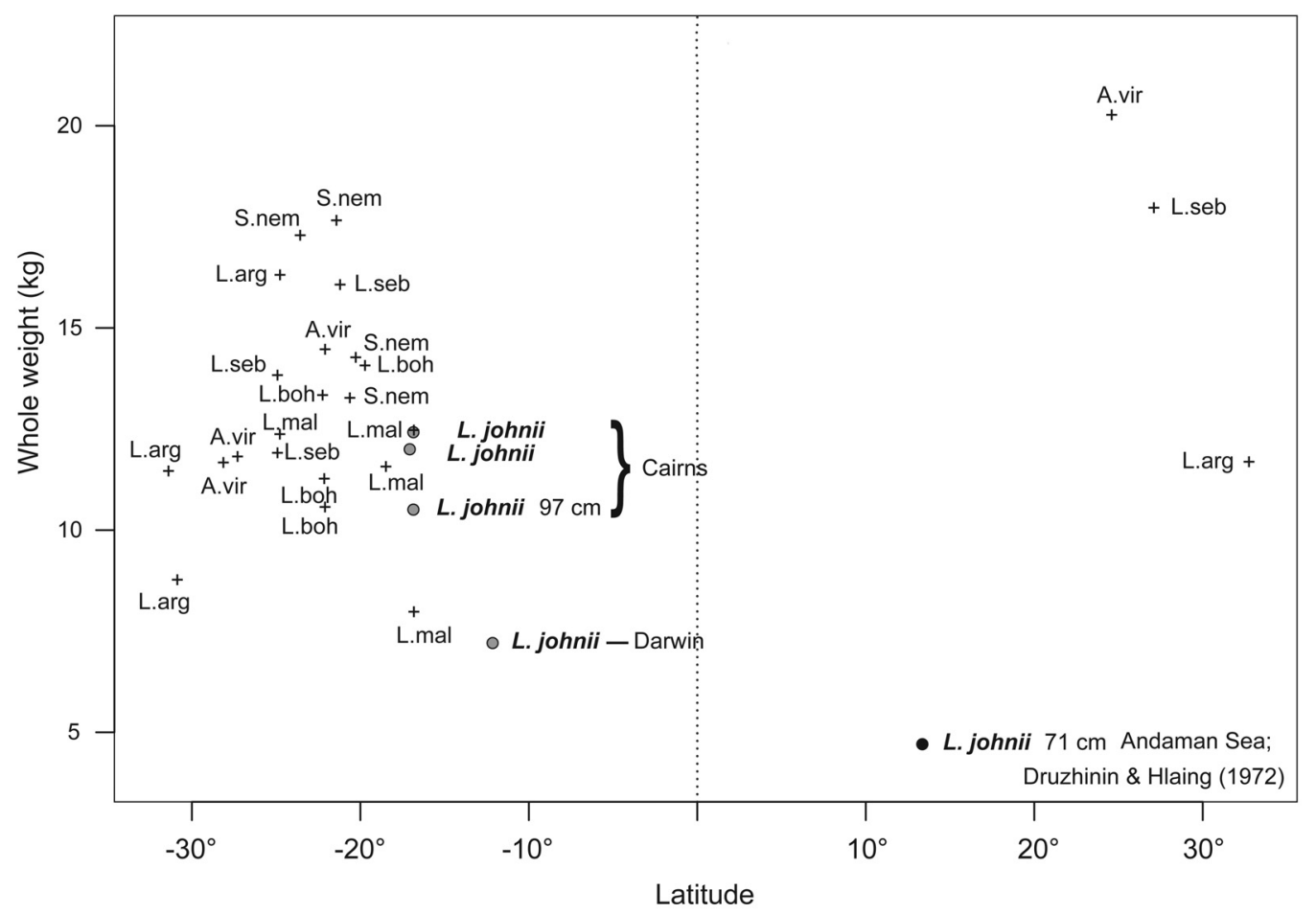

Figure 6

Records of maximum weight of John's Snapper (Lutjanus johnii) and 6 other large lutjanids landed until 2011, shown by latitude. The data (whole weight in kilograms) for each species was provided by the following sources: the International Game Fishing Association, Australian National Sportfishing Association, Australian Angler's Association, and Australian Underwater Federation. The cluster of data for John's Snapper is bracketed for comparison with the data from Darwin and the largest weight reported in the scientific literature, by Druzhinin and Hlaing (1972) (bottom right). The other 6 lutjanids were Mangrove Jack (L. argentimaculatus: L.arg), Twospot Snapper (L. bohar: L.boh), Malabar Snapper (L. malabaricus: L.mal), Emperor Snapper (L. sebae: L.seb), Chinaman Fish (Symphorus nematophorus: S.nem), and Green Jobfish (Aprion virescens: A.vir).

feeding and growth at increasing distance from the equator (see Conover et al., 2009, for review). In fact, the crisper clarity of opaque and translucent zones in otoliths of tropical fishes from latitudes where water temperatures are $5-10^{\circ}$ Celsius cooler may be a physiological product of this counter-gradient variation in growth (see photomicrographs in Choat et al., 2003, 2009; Marriott and Mapstone, 2006; Robertson et al., 2005a).

Pörtner and Knust (2007) proposed a "thermal limitation hypothesis" that natural selection favors individuals that maximize growth and energy efficiency at the expense of ranges of thermal tolerance (see also Pörtner et al., 2008). The underlying concept of oxygen- and capacity-limited thermal tolerance (OCLT) implies that oxygen supply to tissues is optimal between lower and upper temperature limits. Between these limits (termed pejus temperatures), oxygen supply also can be increased to exceed maintenance demand and fuel aerobic metabolism for the performance of growth, foraging, migration, and reproduction.

These "performances" support the fitness of species, and the excess in oxygen availability that supports them is reflected in a species-specific aerobic scope. The aerobic scope is the difference between the lowest and highest rates of aerobic respiration, with an optimum close to the upper pejus temperature. Beyond upper pejus limits, oxygen supply decreases, maintenance demand rises, and aerobic scope begins to decrease (for review, see Pörtner 2012). At suboptimal high temperatures, fish cannot consume enough food to meet increasing metabolic needs because aerobic scope is insufficient to satisfy the increase in oxygen demand from exercise and digestion (Pörtner and Peck, 2010).

Populations of Atlantic Cod (Gadus morhua) also follow James's rule in the Atlantic, where the growth, spawning, and recruitment of this species are well 
known along a latitudinal cline (Pörtner et al., 2008). Permanent physiological differences induced by temperature and climate have been identified in Atlantic Cod populations along that cline, resulting in population-specific patterns of OCLT. The Hb-I(1/1) allele displays an increasing frequency toward the (warmer) south, leading to a higher oxygen affinity at higher temperatures, and this feature is considered to be a microevolutionary adaptation to optimize oxygen transport (Pörtner et al., 2008).

The OCLT concept does not imply strict positive or negative correlations between longevity, maximum size, or growth rate along latitudinal clines. It offers a promising new way forward to use physiological challenges under controlled conditions (see Clark et al., 2012) to disentangle true mechanistic causes (and contradictions) of the temperature-size rule from effects of fishing and unknown environmental differences between regions. This approach may explain why responses in growth rate and maximum size along long latitudinal gradients are inconsistent in statistical correlations used in intensive field studies of tropical fishes. For example, Robertson et al. (2005a) concluded that variation in growth and terminal size is related strongly to both habitat and temperature, yet Trip et al. (2008) proposed that growth and adult size are most responsive to local environmental features unrelated to latitudinal (temperature) effects.

\section{Growth trajectories and length at maturity}

Despite vast differences in the local environments sampled, the basic patterns in the growth curves of John's Snapper are conserved. This snapper species has a relatively gradual growth trajectory through early life, maturing at 6-10 years and at $70-80 \%$ of $L_{\infty}$, and reaching an asymptotic length at $\sim 18-20$ years. The consistent, sex-specific differences in growth rates are consistent with functional gonochorism for John's Snapper, for which there is a higher selective pressure for females to grow to a larger size and have a higher fecundity (Roff, 1983). Longevities $>20$ years are known for many small and large lutjanids (e.g., Heupel et al., 2010; Martinez-Andrade, 2003) and are considered to be beneficial by ensuring a long reproductive life. This life history minimizes the risk that unfavorable events at large scales will result in the loss of a metapopulation. In life history terms, John's Snapper is an "intermediate strategist" falling in the center of a continuum between large species that mature at later ages and have large eggs and those that are long-lived, slowgrowing, and highly fecund species (King and MacFarlane, 2003).

Our demonstration of a longevity that is nearly 3 times that reported from early studies is not surprising, or novel, but it is nonetheless very important to improve meta-analyses, such as analyses with Ecopath and stock reduction models. Compared with the parameters derived by Khan (1986), which appear in the online database FishBase (Froese, 2011), the parameters we have shown for John's Snapper give evidence of a higher longevity (28.6 versus 10 years derived by Khan), lower $K(0.16-0.21$ versus 0.28$)$, about $4 \%$ of the total instantaneous mortality $Z$ (0.146 versus 2.700$)$, and, consequently, about $25 \%$ of the rate of natural mortality $M(\leq 0.146$ versus $\leq 0.590)$.

The estimates of length at maturity of John's Snapper are coarse and preliminary but indicate differences as high as $24 \%$ between the latitudinal limits sampled. Therefore, it is interesting to note that the minimum estimates exceeded predictions from regressions on the basis of $L_{\infty}$ and $L_{\max }$ from published meta-analyses. With our $L_{\max }$ of $990 \mathrm{~mm} \mathrm{FL}$ and $L_{\infty}$ of $843.5 \mathrm{~mm}$ FL for the north Queensland region, we calculated an estimated $L_{\mathrm{m}}$ of 495 $\pm 10 \mathrm{~mm}$ FL using the Binohlan and Froese (2009) method and estimated $L_{\mathrm{m}}$ of $448 \pm 10 \mathrm{~mm}$ FL in the Froese and Binohlan (2000) equation. Martinez-Andrade (2003) generalized that $L_{\mathrm{m}}$ occurred at a length about half (0.52) of the $L_{\infty}$ for lutjanids, producing an even smaller estimate $\left(L_{\mathrm{m}}=438 \mathrm{~mm}\right.$ FL) for John's Snapper. Our estimates were considerably larger at $590 \mathrm{~mm}$ FL for males and 690 $\mathrm{mm}$ FL for females in north Queensland, representing from $59.6 \%$ (males) to $69.7 \%$ (females) of $L_{\max }$ and from $69.9 \%$ to $81.8 \%$ of $L_{\infty}$. The legal limits to fish size at first capture of John's Snapper in Western Australia (300 mm total length) and Queensland (350 $\mathrm{mm}$ total length) do not approach any of the estimates discussed above. The Northern Territory has no size limit.

The northernmost (Arafura Sea) samples were at the smallest extremes of length and otolith weight at age and of gonad weight at length, when compared with samples from the other regions. However, the fishery on the coastal reefs of the Northern Territory, inshore of the Arafura Sea trawl grounds, recorded John's Snapper up to $820 \mathrm{~mm}$ FL and 23 years of age (Hay et al. ${ }^{3}$ ). Of these coastal females, $50 \%$ reached sexual maturity $\left(L_{\mathrm{m} 50}\right)$ at a much larger size of $630 \mathrm{~mm}$ FL (8-10 years) than did Arafura Sea females, although males reached maturity at a similar size $\left(L_{\mathrm{m} 50}=470 \mathrm{~mm} \mathrm{FL}\right)$. There is clearly a need to accurately measure regional length at maturity and establish fecundity-size curves to fully understand the nested hierarchy within growth curves. In general terms, larger adults of tropical fish populations farther from the equator might be expected to have much larger ovaries (and hence batch fecundity) and a longer spawning life in comparison with their smaller counterparts close to the equator. However, there is no evidence that recruitment rates are higher for populations at these margins. Instead, Pörtner et al. (2008) proposed that recruitment rates should show a dome-shaped distribution about an optimal temperature range.

\footnotetext{
${ }^{3}$ Hay T., I. Knuckey, C. Calogeras, and C. Errity. 2005. NT coastal reef fish: population and biology of the golden snapper. Fishnote No: 21 Department of Primary Industry, Fisheries and Mines, Darwin, Northern Territory, Australia, 4 p. [Available from http://www.nt.gov.au/d/Content/File/p/ Fishnote/FN21.pdf.]
} 
The appearance of a U-shaped relationship between record sizes of lutjanids and latitude among 3 genera highlights the chronic lack of basic length and weight information on equatorial and Asian populations of lutjanids in the Indo-West Pacific. These records also suggest that James's rule may apply in age-based studies when such studies are eventually undertaken in those countries.

\section{Conclusions}

As with some studies of site-attached coral reef fishes, our findings of larger terminal size, faster growth, and larger size at maturity for John's Snapper farthest from the equator agree with James's rule but do not agree with the presumption of "slower growth in colder water" of the temperature-size rule for ectotherms. Further, age-based studies alone cannot resolve the variability in the growth response reported in some tropical studies. More powerful insights can be obtained through the use of the concept of OCLT and measurement of physiological response to exercise and thermal challenges in populations along latitudinal clines.

The existence of older, larger John's Snapper in the southern portion of the range of this species has raised some compelling questions concerning the lifetime reproductive output and subsequent recruitment rates of tropical fish populations at the warmer core and cooler limits of their ranges. If recruitment also is marginal at thermal limits, then is the development of larger gonads each year over a longer life in cooler waters a wasted investment for John's Snapper or is it an adaptation to episodic recruitment success? Such questions can be investigated only if age-based studies of fish demography are accompanied by information on sizefecundity curves and egg size and quality, along with some relative indices of recruitment.

\section{Acknowledgments}

We wish to thank all the tackle store proprietors, numerous anglers, and spearfishing individuals who provided specimens for use in this study or assisted with fieldwork. From the fishing community, we would like to thank, in particular, A. J. McDougall, D. Donald, A. Mead, E. Riddle, M. Kenway, S. Boyle, and P. Hazard. Archived otoliths and fish frames were supplied also by D. Milton, G. McPherson, M. Sheaves, and A. Coleman. Field and laboratory support was provided by R. Steckis, J. Jenke, C. Skepper, and B. Robertson. We especially appreciate the critical and constructive advice of 3 reviewers including J. H. Choat and A. J. McDougall.

\section{Literature cited}

Allen, G. R.

1985. FAO species catalogue. Vol. 6. Snappers of the world. An annotated and illustrated catalogue of lutjanid species known to date. FAO Fish. Synop. 125, 208 p. FAO, Rome.

Allman, R. J., and L. A. Goetz.

2009. Regional variation in the population structure of gray snapper, Lutjanus griseus, along the west Florida shelf. Bull. Mar. Sci. 84:315-330.

Allman, R. J., G. R. Fitzhugh, K. J. Starzinger, and R. A. Farsky.

2005. Precision of age estimation in red snapper (Lutjanus campechanus). Fish. Res. 73:123-133.

Arendt, J. D.

2011. Size-fecundity relationships, growth trajectories, and the temperature-size rule for ectotherms. Evolution 65:43-51.

Atkinson, D.

1994. Temperature and organism size-a biological law for ectotherms. Adv. Ecol. Res. 25:1-58.

Beamish, R. J., and D. A. Fournier.

1981. A method for comparing the precision of a set of age determinations. Can. J. Fish. Aquat. Sci. 38:982-983.

Berrigan, D., and E. L. Charnov.

1994. Reaction norms for age and size at maturity in response to temperature: a puzzle for life historians. Oikos 70:474-478.

Berumen, M. L., E. D. L. Trip, M. S. Pratchett, and J. H. Choat. 2012. Differences in demographic traits of four butterflyfish species between two reefs of the Great Barrier Reef separated by $1,200 \mathrm{~km}$. Coral Reefs $31: 169-177$.

Binohlan, C., and R. Froese.

2009. Empirical equations for estimating maximum length from length at first maturity. J. Appl. Ichthyol. 25:611-613.

Blackburn, T. M., K. J. Gaston, and N. Loder.

1999. Geographic gradients in body size: a clarification of Bergmann's rule. Divers. Distrib. 5:165-174.

Burton, M. L.

2001. Age, growth, and mortality of gray snapper, Lutjanus griseus, from the east coast of Florida. Fish. Bull. 99:254-265.

Campana, S. E., M. C. Annand, and J. I. McMillan. 1995. Graphical and statistical methods for determining the consistency of age determinations. Trans. Am. Fish. Soc. 124:131-138.

Cappo, M., P. Eden, S. J. Newman, and S. Robertson.

2000. A new approach to tetracycline validation of the periodicity and timing of opaque zone formation in the otoliths of 11 species of Lutjanus from the central Great Barrier Reef. Fish. Bull. 98:474-488.

Cerrato, R. M.

1990. Interpretable statistical tests for growth comparisons using parameters in the von Bertalanffy equation. Can. J. Fish. Aquat. Sci. 47:1416-1426.

Choat, J. H., and D. R. Robertson.

2002. Age-based studies. In Coral reef fishes: dynamics and diversity in a complex ecosystem (P. F. Sale, ed.), p. 57-80. Academic Press, San Diego, CA. 
Choat, J. H., D. R. Robertson, J. L. Ackerman, and J. M. Posada.

2003. An age-based demographic analysis of the Caribbean stoplight parrotfish Sparisoma viride. Mar. Ecol. Prog. Ser. 246:265-277.

Choat, J. H., J. P. Kritzer, and D. R. Robertson. 2009. Ageing in coral reef fishes: do we need to validate the periodicity of increment formation for every species of fish for which we collect age-based demographic data? In Tropical fish otoliths: information for assessment, management and ecology (B. S. Green, B. D. Mapstone, G. Carlos, and G. A. Begg, eds.), p. 23-45. Springer, New York.

Clark, T. D., M. R. Donaldson, S. Pieperhoff, S. M. Drenner, A. Lotto, S. J. Cooke, S. G. Hinch, D. A. Patterson, and A. P. Farrell.

2012. Physiological benefits of being small in a changing world: responses of coho salmon (Oncorhynchus kisutch) to an acute thermal challenge and a simulated capture event. PLoS ONE 7(6):e39079.

Conover, D. O., J. J. Brown, and A. Ehtisham.

1997. Countergradient variation in growth of young striped bass (Morone saxatilis) from different latitudes. Can. J. Fish. Aquat. Sci. 54:2401-2409.

Conover, D. O., T. A. Duffy, and L. A. Hice.

2009. The covariance between genetic and environmental influences across ecological gradients: reassessing the evolutionary significance of countergradient and cogradient variation. Ann. N.Y. Acad. Sci. 1168:100-129.

Druzhinin, A. D.

1970. The range and biology of snappers (Fam. Lutjanidae). J. Ichthyol. 10:717-736.

Druzhinin, A. D., and U. P. Hlaing.

1972. Observations on the trawl fishery of southern Burma. In Proc. Indo-Pac. Fish. Coun, Session 13, Sect. III Tech. Pap., Symposium on Demersal Fisheries; Brisbane, Australia, 14-25 October 1968, p. 151-209. IPFC (Indo-Pacific Fisheries Council) Secretariat, FAO Regional Office for Asia and the Far East, Bangkok, Thailand.

Fisher, J. A. D., K. T. Frank, and W. C. Leggett.

2010. Breaking Bergmann's rule: truncation of Northwest Atlantic marine fish body sizes. Ecology 91:2499-2505.

Froese, R.

2011. The science in FishBase. In Ecosystem approaches to fisheries: a global perspective (V. Christensen and J. Maclean, eds.), p. 47-54. Cambridge Univ. Press, Cambridge, UK.

Froese, R., and C. Binohlan.

2000. Empirical relationships to estimate asymptotic length, length at first maturity and length at maximum yield per recruit in fishes, with a simple method to evaluate length frequency data. J. Fish Biol. 56:758-773.

Fry, G. C., and D. A. Milton.

2009. Age, growth and mortality estimates for populations of red snappers Lutjanus erythropterus and $L$. malabaricus from northern Australia and eastern Indonesia. Fish. Sci. 75:1219-1229.

Haddon, M.

2001. Modelling and quantitative methods in fisheries, 424 p. Chapman and Hall/CRC Press, Boca Raton, FL.
Heupel, M. R., A. Penny, A. J. Williams, J. P. Kritzer, D. J. Welch, R. J. Marriott, C. R. Davies, and B. D. Mapstone. 2010. Demographic characteristics of exploited tropical lutjanids: a comparative analysis. Fish. Bull. 108:420-432.

Hoenig, J. M.

1983. Empirical use of longevity data to estimate mortality rates. Fish. Bull. 82: 898-902.

Khan, M. G.

1986. Age, growth and mortality rates of the red snapper (Lutjanus johnii Bloch) of the Bay of Bengal, Bangladesh. Bangladesh J. Agric. 11(2):49-61.

King, J. R., and G. A. McFarlane.

2003. Marine fish life history strategies: applications to fishery management. Fish. Manage. Ecol. 10:249-264.

Kiso, K., and M. I. Mahyam.

2003. Distribution and feeding habits of juvenile and young John's snapper Lutjanus johnii in the Matang mangrove estuary, west coast of Peninsular Malaysia. Fish. Sci. 69:563-568.

Marriott, R. J., and M. Cappo.

2000. Comparative precision and bias of five different ageing methods for the large tropical snapper Lutjanus johnii. Asian Fish. Sci. 13:149-160.

Marriott, R. J., and B. D. Mapstone.

2006. Geographic influences on and the accuracy and precision of age estimates for the red bass, Lutjanus bohar (Forsskal 1775): a large tropical reef fish. Fish. Res. 80:322-328.

Martinez-Andrade, F.

2003. A comparison of life histories and ecological aspects among snappers (Pisces: Lutjanidae). Ph.D. diss., 194 p. Louisiana State Univ., Baton Rouge, LA.

Newman, S., M. Cappo, and D. McB. Williams.

2000. Age, growth, mortality rates and corresponding yield estimates using otoliths of the tropical red snappers, Lutjanus erythropterus, L. malabaricus and $L$. sebae, from the central Great Barrier Reef. Fish. Res. 48:1-14.

Pauly, D., S. Samiblya Jr., and S. Opitz.

1993. Estimates of relative food consumption by fish and invertebrate populations, required for modelling the Bolinao Reef Ecosystem, Philippines. In Trophic models of aquatic ecosystems (V. Christensen and D. Pauly, eds.), p. 236-251. ICLARM Conference Proceedings 26, International Center for Living Aquatic Resources Management, Metro Manila, Philippines.

Pörtner, H. O.

2012. Integrating climate-related stressor effects on marine organisms: unifying principles linking molecule to ecosystem-level changes. Mar. Ecol. Prog. Ser. 470:273-290.

Pörtner, H. O., C. Bock, R. Knust, G. Lannig, M. Lucassen, F. C. Mark, and F. J. Sartoris.

2008. Cod and climate in a latitudinal cline: physiological analyses of climate effects in marine fishes. Clim. Res. 37:253-270.

Pörtner, H. O., and R. Knust.

2007. Climate change affects marine fishes through the oxygen limitation of thermal tolerance. Science 315:95-97.

Pörtner, H. O., and M. A. Peck.

2010. Climate change effects on fishes and fisheries: towards a cause-and-effect understanding. J. Fish Biol. 77:1745-1779. 
Robertson, D. R., J. L. Ackerman, J. H. Choat, J. M. Posada, and J. Pitt.

2005a. Ocean surgeonfish Acanthurus bahianus. I. The geography of demography. Mar. Ecol. Prog. Ser. 295:229-244.

Robertson, D. R., J. H. Choat, J. M. Posada, J. Pitt, and J. L. Ackerman.

2005b. Ocean surgeonfish Acanthurus bahianus. II. Fishing effects on longevity, size and abundance? Mar. Ecol. Prog. Ser. 295:245-256.

Roff, D. A.

1983. An allocation model of growth and reproduction in fish. Can. J. Fish. Aquat. Sci. 40:1395-1404.

Saari, C. R.

2011. Comparison of the age and growth of red snapper (Lutjanus campechanus) amongst habitats and regions in the Gulf of Mexico. M.S. diss., 134 p. Louisiana State Univ., Baton Rouge, LA.
Tanaka, K., Y. Hanamura, V. C. Chong, S. Watanabe, A. Man, F. M. Kassim, M. Kodama, and T. Ichikawa.

2011. Stable isotope analysis reveals ontogenetic migration and the importance of a large mangrove estuary as a feeding ground for juvenile John's snapper Lutjanus johnii. Fish. Sci. 77:809-816.

Travers, M. J., I. C. Potter, K. R. Clarke, S. J. Newman, and J. B. Hutchins.

2009. The inshore fish faunas over soft substrates and reefs on the tropical west coast of Australia differ and change with latitude and bioregion. J. Biogeogr. 37:148-169.

Trip, E. L., J. H. Choat, , D. T. Wilson, and D. R. Robertson.

2008. Inter-oceanic analysis of demographic variation in a widely distributed Indo-Pacific coral reef fish. Mar. Ecol. Prog. Ser. 373:97-109. 